\title{
Article \\ Protective Effects of Annatto Tocotrienol and Palm Tocotrienol-Rich Fraction on Chondrocytes Exposed to Monosodium Iodoacetate
}

\author{
Kok-Lun Pang ${ }^{1,2}$, Norzana Abd Ghafar ${ }^{3}$, Ima Nirwana Soelaiman ${ }^{1}$ and Kok-Yong Chin ${ }^{1, *(D)}$ \\ 1 Department of Pharmacology, Faculty of Medicine, Universiti Kebangsaan Malaysia, Cheras, \\ Kuala Lumpur 56000, Malaysia; kok-lun.pang@newcastle.edu.my (K.-L.P.); imasoel@gmail.com (I.N.S.) \\ 2 Newcastle University Medicine Malaysia, Iskandar Puteri 79200, Malaysia \\ 3 Department of Anatomy, Faculty of Medicine, University Kebangsaan Malaysia, Jalan Yaacob Latif, \\ Bandar Tun Razak, Cheras, Kuala Lumpur 56000, Malaysia; norzana@ukm.edu.my \\ * Correspondence: chinkokyong@ppukm.ukm.edu.my; Tel.: +60-3-91459573
}

check for updates

Citation: Pang, K.-L.; Ghafar, N.A.; Soelaiman, I.N.; Chin, K.-Y. Protective Effects of Annatto Tocotrienol and Palm Tocotrienol-Rich Fraction on Chondrocytes Exposed to Monosodium Iodoacetate. Appl. Sci. 2021, 11, 9643. https://doi.org/ 10.3390/app11209643

Academic Editors: Paolo Alberton and Emeline Perrier-Groult

Received: 17 August 2021

Accepted: 12 October 2021

Published: 15 October 2021

Publisher's Note: MDPI stays neutral with regard to jurisdictional claims in published maps and institutional affiliations.

Copyright: (c) 2021 by the authors. Licensee MDPI, Basel, Switzerland. This article is an open access article distributed under the terms and conditions of the Creative Commons Attribution (CC BY) license (https:// creativecommons.org/licenses/by/ $4.0 /)$.
Featured Application: The study provides important information for developing annatto tocotrienol and palm tocotrienol-rich fraction as potential therapeutic agents against osteoarthritis.

\begin{abstract}
Background: This study aimed to compare the chondroprotective efficacy and mechanism of annatto tocotrienol (AnTT) and palm tocotrienol-rich fraction (PT3) using SW1353 chondrocytes treated with monosodium iodoacetate (MIA). Methods: The chondrocytes were incubated with AnTT or PT3 in advance or concurrently with MIA for $24 \mathrm{~h}$. The viability of the cells was tested with an MTT assay. The 8-isoprostane F2- $\alpha$, extracellular matrix proteins, metalloproteinase and sex-determining region Y box protein 9 (SOX9) levels were determined using immunoassays. Results: AnTT and PT3 reversed an MIA-induced decrease in chondrocyte viability when incubated together with MIA $(p<0.05)$. Prior incubation with both mixtures did not produce the same effects. AnTT and PT3 cotreatment could suppress 8-isoprostane F2- $\alpha$ level in chondrocytes exposed to MIA $(p<0.01)$. Coexposure to tocotrienols and MIA increased the type II collagen/type I collagen ratio in chondrocytes $(p<0.01)$. In addition, the co-exposure of AnTT and MIA for $24 \mathrm{~h}$ significantly upregulated SOX9, type II collagen and aggrecan levels $(p<0.05)$, which was not observed with co-exposure of PT3 and MIA, AnTT or PT3 exposure alone. Conclusion: AnTT and PT3 could prevent a reduction in chondrocyte viability following MIA exposure by reducing oxidative stress. In addition, AnTT might induce self-repair and anabolic activities in chondrocytes challenged with MIA.
\end{abstract}

Keywords: cartilage; collagen; osteoarthritis; oxidative stress; SOX9; vitamin E

\section{Introduction}

Osteoarthritis (OA) is a degenerative disease affecting movable joints of the body. It is characterised by pain, swelling, stiffness, and decreased motion range of the joint, which adversely affect patients' mobility [1]. A recent meta-analysis summarised that the global prevalence of knee OA was $16 \%$ in the population aged $\geq 15$ years and $22.9 \%$ in the population $\geq 40$ years, with a female to male ratio of 1.69 [2]. The Global Burden of Disease Study 2019 reported a $27.5 \%$ increase in the prevalence of OA and $27.5 \%$ increase in disability adjusted life years due to OA between 2010 and 2019 [3]. OA (except hand OA) is also associated with increased risk of cardiovascular disease and its associated mortality, probably due to shared risk factors and OA-associated physical inactivity [4,5].

Cartilage is one of the joint tissues most affected by OA. Cartilage homeostasis is maintained by chondrocytes, which synthesise and replenish the collagenous extracellular matrix [6]. Accumulated evidence has demonstrated the involvement of the hypocellularity 
of cartilage or chondrocyte cell death in OA initiation [6-8]. Chondrocytes with mechanical, oxidative or inflammation-induced damage have poor recovery capacity due to the alymphatic and avascular condition in the cartilage $[9,10]$. The function and metabolism of damaged chondrocytes will be compromised. Ultimately, the chondrocytes will die off via apoptosis and lead to hypocellularity, matrix depletion and degradation of cartilage $[7,11]$. Additionally, the leaked or degraded cellular content from dead chondrocytes, as well as the cartilage debris, could activate the inflammatory cascades and the release of pro-inflammatory mediators by joint tissues and immune cells, leading to synovitis [12]. In turn, these mediators induce the release of metalloproteinase by chondrocytes and provoke further cartilage damage $[13,14]$. Inflammation and oxidative stress are two intricately linked process in OA. Pro-inflammatory cytokines such as interleukin-1 $\beta$ and tumour necrosis factor-alpha induce nitric oxide production and mitochondrial dysfunction, which contribute to chondrocyte malfunction and apoptosis [15]. A previous study showed that monosodium iodoacetate (MIA), a glycolysis inhibitor, induced proliferation arrest and oxidative stress in chondrocytes in vitro [16]. Therefore, the MIA model may represent a suitable model to study early chondrocyte damage.

The primary pharmacological treatment of OA aims to relieve its symptoms, e.g., nonsteroidal anti-inflammatory agents and paracetamol relieve joint pain in OA patients [17]. Intra-articular corticosteroid injection is effective against joint pain, but it may cause local and systemic side effects [18]. Besides, evidence for the efficacy of several common supplements for $\mathrm{OA}$, such as glucosamine, chondroitin and avocado or soybean unsaponifiables for OA management, has not been conclusive according to meta-analysis [19]. The failure of pharmacological interventions allows the condition to progress to end-stage OA, necessitating joint replacement or arthroplasty. Arthroplasty is a costly procedure and introduces the risk of infection, loosening of prosthetics and periprosthetic fractures [20,21]. Therefore, the search for novel agents with better efficacy to treat OA is ongoing.

Tocotrienol, a subfamily of vitamin $\mathrm{E}$ found in botanical oil, has been reported to protect chondrocytes and joint health. Palm tocotrienol $(30 \mathrm{mg} / \mathrm{kg}), \gamma$-tocotrienol $(5 \mathrm{mg} / \mathrm{kg})$ and $\delta$-tocotrienol $(10 \mathrm{mg} / \mathrm{kg})$ isomers have been tested in rat models of rheumatoid arthritis (RA) induced by collagen II [22-24]. They were reported to prevent paw oedema, joint deterioration and oxidative stress in rats with RA [22-24]. In addition, annatto tocotrienol (AnTT; $100 \mathrm{mg} / \mathrm{kg} /$ day) has been shown to reduce cartilage damage and its associated cartilage degradation markers in rats administered intraarticularly with MIA [25]. Another study on the effects of palm tocotrienol-rich (PT3, $100 \mathrm{mg} / \mathrm{kg}$ ) combined with glucosamine sulphate $(250 \mathrm{mg} / \mathrm{kg})$ using a similar animal model demonstrated reduced circulating degradation markers and improved grip strength [26]. However, the currently available studies on vitamin $\mathrm{E}$ and cartilage damage are predominantly on $\alpha$-tocopherol, the major isoform of vitamin in the human diet and body [27]. Thus, evidence on the direct action of tocotrienol on chondrocytes is very limited.

This study aimed to determine the effects of annatto and palm-derived vitamin $\mathrm{E}$ mixture on chondrocyte damage induced with MIA. Vitamin E derived from annatto is rich in $\delta$-tocotrienol but contains a negligible amount of $\alpha$-tocopherol [28]. On the other hand, palm vitamin E contains $\alpha$-tocopherol, along with $\alpha-, \beta-, \delta$ - and $\gamma$-tocotrienol [29]. This study assessed whether this compositional difference could give rise to distinct chondroprotective actions in MIA-mediated chondrocyte damage. Both pre-treatment and concurrent treatment models were tested in this study. It was hypothesised that AnTT and PT3 could prevent viability suppression of chondrocytes induced by MIA and preserve their function. The findings of this study could provide further evidence on the use of tocotrienol in preventing chondrocyte damage. 


\section{Materials and Methods}

\subsection{Materials}

All the chemicals used in this study were purchased from Sigma-Aldrich unless stated otherwise. A $100 \mathrm{mM}$ MIA stock solution was prepared by dissolving it in dimethyl sulfoxide. The stock solution was then aliquoted and kept at $-80^{\circ} \mathrm{C}$ until use. The AnTT was a gift from American River Nutrition (Hadley, USA) and contained $84 \% \delta$-tocotrienol and $16 \% \gamma$-tocotrienol (Lot Number: \#18FA-1270, purity 70\%). The PT3 was a gift from Excelvite Sdn. Bhd. (Chemor, Malaysia) and contained 21.9\% $\alpha$-tocopherol, 24.7\% $\alpha$ tocotrienol, $4.5 \% \beta$-tocotrienol, 36.9\% $\gamma$-tocotrienol and $12.0 \% \delta$-tocotrienol (Batch Number: A1/50/0450_1_220318, purity 50\%). Stock solutions of AnTT and PT3 were prepared according to the methodologies used in our previous studies with slight modifications in concentration $[30,31]$. Briefly, AnTT and PT3 stock solutions were firstly dissolved in absolute ethanol to a concentration of 0.1 and $0.2 \mathrm{~g} / \mathrm{mL}$ respectively, aliquoted and kept at $-80{ }^{\circ} \mathrm{C}$ until use. The day before treatment, $45 \mu \mathrm{L}$ tocotrienol stock solution was mixed with $60 \mu \mathrm{L}$ sterile foetal bovine serum (FBS) and incubated at $37^{\circ} \mathrm{C}$ for $24 \mathrm{~h}$. After that, $105 \mu \mathrm{L}$ of absolute ethanol was added to the mixture and followed by $90 \mu \mathrm{L}$ of complete media. The same procedure was employed for the vehicle control (VC) group using $45 \mu \mathrm{L}$ of absolute ethanol. The entire process of MIA and tocotrienol stock preparation, storage, incubation and treatment were protected from direct light exposure.

\subsection{Cell Lines}

SW1353 chondrocytes were purchased from American Type Culture Collection (catalogue no. HTB 94) and cultured in a high glucose Dulbecco's modified Eagle's medium (Nacalai Tesque, Japan; catalogue no. 08458-16) that contained $4 \mathrm{mM} \mathrm{L-glutamine,} 1 \mathrm{mM}$ sodium pyruvate, $10 \%$ FBS (Thermo Fisher Scientific, Waltham, MA, USA; catalogue no. 10270-106) and 1\% antibiotic-antimycotic solution (Thermo Fisher Scientific, Waltham, MA, USA; catalogue no. $15240-062$ ) at $37^{\circ} \mathrm{C}$ in an incubator with humidified air and $5 \%$ carbon dioxide. These cells were passaged every 2 days to maintain the cells in logarithmic growth. The cells in early passages (3rd-10th passages) were used in the experiment.

\subsection{Cytotoxicity Assay}

The cytotoxicity of AnTT and PT3 was determined using the yellow tetrazolium salt 3-(4,5-dimethylthiazol-2-yl)-2,5-diphenyltetrazolium bromide (MTT) according to previous studies with slight modification [16,30,32]. Briefly, $100 \mu \mathrm{L}$ of SW1353 chondrocytes $\left(5 \times 10^{4}\right.$ cells $\left./ \mathrm{mL}\right)$ were seeded in a 96-well plate with complete media for $24 \mathrm{~h}$. Subsequently, the media were removed and replaced with $100 \mu \mathrm{L}$ of complete media with a series of concentrations of AnTT or PT3 for another $24 \mathrm{~h}$. At the end of the treatment, $20 \mu \mathrm{L}$ of MTT solution $(5 \mathrm{mg} / \mathrm{mL})$ was added to each well and then further incubated for another $4 \mathrm{~h}$ inside a $37^{\circ} \mathrm{C}$ incubator. The optical density (OD) of each well was measured at the wavelength of $570 \mathrm{nM}$ using a Multiskan GO microplate reader (Thermo Fisher Scientific, Vantaa, Finland). The viability of the treated cells was calculated by dividing the OD of the treated group with the OD value of the VC and multiplied by $100 \%$.

In certain experiments, SW1353 chondrocytes were challenged with MIA in its halfmaximal inhibitory concentration $\left(\mathrm{IC}_{50}\right)$ value $(31.5 \mu \mathrm{M})$ determined from our previous study [16], with/without prior or concurrent treatment of tocotrienols. In the preventive model, $100 \mu \mathrm{L}$ of SW1353 chondrocytes $\left(5 \times 10^{4}\right.$ cells $\left./ \mathrm{mL}\right)$ were seeded in a 96-well plate with complete media for $24 \mathrm{~h}$. Subsequently, the media were removed and the cells were pre-treated with $100 \mu \mathrm{L}$ of fresh complete media with a series of concentrations of AnTT or PT3 for another $24 \mathrm{~h}$. Lastly, the media were replaced again with $100 \mu \mathrm{L}$ of fresh complete media with MIA. For the treatment model, $100 \mu \mathrm{L}$ of SW1353 chondrocytes $\left(5 \times 10^{4}\right.$ cells $\left./ \mathrm{mL}\right)$ were seeded in a similar condition as the preventive model for $24 \mathrm{~h}$. Subsequently, the media were replaced with $100 \mu \mathrm{L}$ of fresh complete media with a series of concentrations of AnTT or PT3 and MIA ( $\mathrm{IC}_{50}$ ) for another $24 \mathrm{~h}$. An MTT assay was conducted at the end of the treatment. The viability of cells was calculated as a percentage 
relative to the VC, as mentioned previously. The effective concentrations of AnTT and PT3 that proved to be protective against MIA-induced reduction in cell viability were used in the subsequent experiments.

\subsection{Whole Cell Lysate Preparation}

The lysate preparation was conducted according to the methodology used in our previous study [16]. Briefly, SW1353 chondrocytes were seeded in $100 \mathrm{~mm}$ culture dishes ( $5 \times 10^{4}$ cells $/ \mathrm{mL} ; 15.5 \mathrm{~mL}$ of cells; 3 culture dishes per group) for $24 \mathrm{~h}$. Subsequently, the SW1353 cells were challenged with MIA ( $\left.\mathrm{IC}_{50}\right)$ with or without the presence of AnTT (10 and $20 \mu \mathrm{g} / \mathrm{mL}$ ) or PT3 $(25$ and $50 \mu \mathrm{g} / \mathrm{mL}$ ) for $24 \mathrm{~h}$. Then, the media with the floated cells were collected and combined with the trypsinised cells. The entire mixture was centrifuged and washed twice with ice-cold phosphate buffer saline at $200 \times g$ for $5 \mathrm{~min}$. The cell pellets were then lysed with $500 \mu \mathrm{L}$ of Qproteome mammalian lysis buffer (Qiagen, Hilden, Germany) containing protease inhibitors for $15 \mathrm{~min}$ on ice with a gentle intermittent vortex. Subsequently, the contents were centrifuged at $10,000 \times g$ at $4{ }^{\circ} \mathrm{C}$ for $15 \mathrm{~min}$. Finally, the pellets were discarded and only the supernatants were collected as lysates. The lysate preparation was repeated at least three times. The protein concentrations of lysates were determined by using the microtiter format of Bio-Rad Protein Assay concentrated dye reagent (Bio-Rad Laboratories, Hercules, CA, USA). Lastly, the lysates were diluted into $1 \mathrm{mg} / \mathrm{mL}$ (final volume $1.2 \mathrm{~mL}$ ) for the quantitative detection of proteins of interest. All the lysates were kept at $-80{ }^{\circ} \mathrm{C}$ until further analysis.

\subsection{Enzyme-Linked Immunosorbent Assay (ELISA)}

The human 8-isoprostane F2- $\alpha$ level (catalogue no. E4805Hu) was determined using sandwiched enzyme-linked immunoassay (ELISA) kit from Bioassay Technology Laboratory (Shanghai, China). Briefly, $40 \mu \mathrm{L}$ of cell lysates $(1 \mathrm{mg} / \mathrm{mL}$; in duplicate) were mixed with $10 \mu \mathrm{L}$ of free biotinylated human 8-isoprostane F2- $\alpha$ antibody in the 96-well plate pre-coated with human 8-isoprostane F2- $\alpha$ antibody. The standard solutions (50 $\mu \mathrm{L}$; in serial concentration) were added separately into another 2 rows of wells. Subsequently, all the sample and standard wells (except the blank) were added to with $50 \mu \mathrm{L}$ of streptavidinlinked horseradish peroxidase (HRP) reagent and the 96-well plate was then incubated at $37^{\circ} \mathrm{C}$ for $1 \mathrm{~h}$. Subsequently, the plate was washed 5 times with wash buffer solution and blot-dried with paper towels. Immediately, $100 \mu \mathrm{L}$ of pre-mixed substrate Solution $\mathrm{A}$ and $\mathrm{B}$ was added to each well and the plate was further incubated at $37^{\circ} \mathrm{C}$ for $10 \mathrm{~min}$. Lastly, $50 \mu \mathrm{L}$ of stop solution was added to stop the colourimetric reaction and the absorbance was measured using Multiskan GO microplate reader (Thermo Fisher Scientific, Vantaa, Finland) at the wavelength of $450 \mathrm{~nm}$. The absolute levels of 8-isoprostane F2- $\alpha$ were determined based on the standard curve derived from the standard solutions with known concentration.

The human collagen type I $\alpha 1$ (COL1 $\alpha 1$; catalogue no. E-EL-H0869), collagen type II $\alpha 1$ (COL2 $\alpha 1$; catalogue no. E-EL-H0777), sex-determining region Y box protein 9 (SOX9; catalogue no. E-EL-H1349), a disintegrin and metalloproteinase with thrombospondin type 1 Motif 4 (ADAMTS4; catalogue no. E-EL-H0266) and aggrecan (catalogue no. E-EL-H0294) levels were determined by using the sandwiched ELISA kits from Elabscience (Houston, Texas, USA) according to the manufacturer's protocol. Briefly, $100 \mathrm{uL}$ of standard solution (in serial concentration) and lysates were added $(1 \mathrm{mg} / \mathrm{mL})$ in duplicate into the 96-well plates pre-coated with respective specific antibodies. The plates were then sealed and incubated at $37^{\circ} \mathrm{C}$ for $90 \mathrm{~min}$. After that, the entire content of the wells was removed and replaced with $100 \mu \mathrm{L}$ of respective biotinylated detection antibody working solution. Next, the plates were incubated at $37^{\circ} \mathrm{C}$ for another $1 \mathrm{~h}$ and followed by 3 times of washing with wash buffer solution. Subsequently, $100 \mu \mathrm{L}$ of HRP conjugate working solution was added, and the plates were incubated again at $37^{\circ} \mathrm{C}$ for $30 \mathrm{~min}$. The plates were then washed 5 times with wash buffer solution, followed by the addition of $90 \mu \mathrm{L}$ of substrate reagent solution and incubated at $37^{\circ} \mathrm{C}$ for another $15 \mathrm{~min}$. A $50 \mu \mathrm{L}$ of stop solution was then 
added into the wells, and the absorbance was measured using Multiskan GO microplate reader (Thermo Fisher Scientific, Vantaa, Finland) at $450 \mathrm{~nm}$. The levels of proteins of interest were determined based on the respective standard curves.

\subsection{Statistical Analysis}

Statistical analysis was conducted by using SPSS software for Windows, version 25. The normality of data was tested and a Box-Cox data transformation was performed on non-normally distributed data before parametric testing [33]. Most of the data (except for COL $2 \alpha 1 /$ COL $1 \alpha 1$ ratio, SOX9, aggrecan and ADAMTS4 levels) were not normally distributed, potentially due to the presence of outliers. Mean differences between multiple groups were analysed using a one-way analysis of variance with Tukey or Dunnett's T3 post hoc analysis. A $p$-value of less than 0.05 was considered statistically significant. At least 3 independent experiments were conducted for all parameters. The data were displayed in mean \pm standard error of mean (SEM).

\section{Results}

\subsection{Cytotoxicity of AnTT and PT3 on SW1353 Chondrocytes}

The cytotoxicity of AnTT and PT3 on SW1353 chondrocytes over $24 \mathrm{~h}$ treatment was determined using an MTT assay (Figure 1). AnTT was cytotoxic to SW1353 chondrocytes at concentrations $\geq 30 \mu \mathrm{g} / \mathrm{mL}$ (all $p>0.05$ ), while PT3 was cytotoxic at concentrations $\geq 100 \mu \mathrm{g} / \mathrm{mL}$ (all $p<0.01$ ). Therefore, the non-cytotoxic concentrations of AnTT $(\leq 20 \mu \mathrm{g} / \mathrm{mL})$ and PT3 $(\leq 50 \mu \mathrm{g} / \mathrm{mL})$ were used in the subsequent experiment.
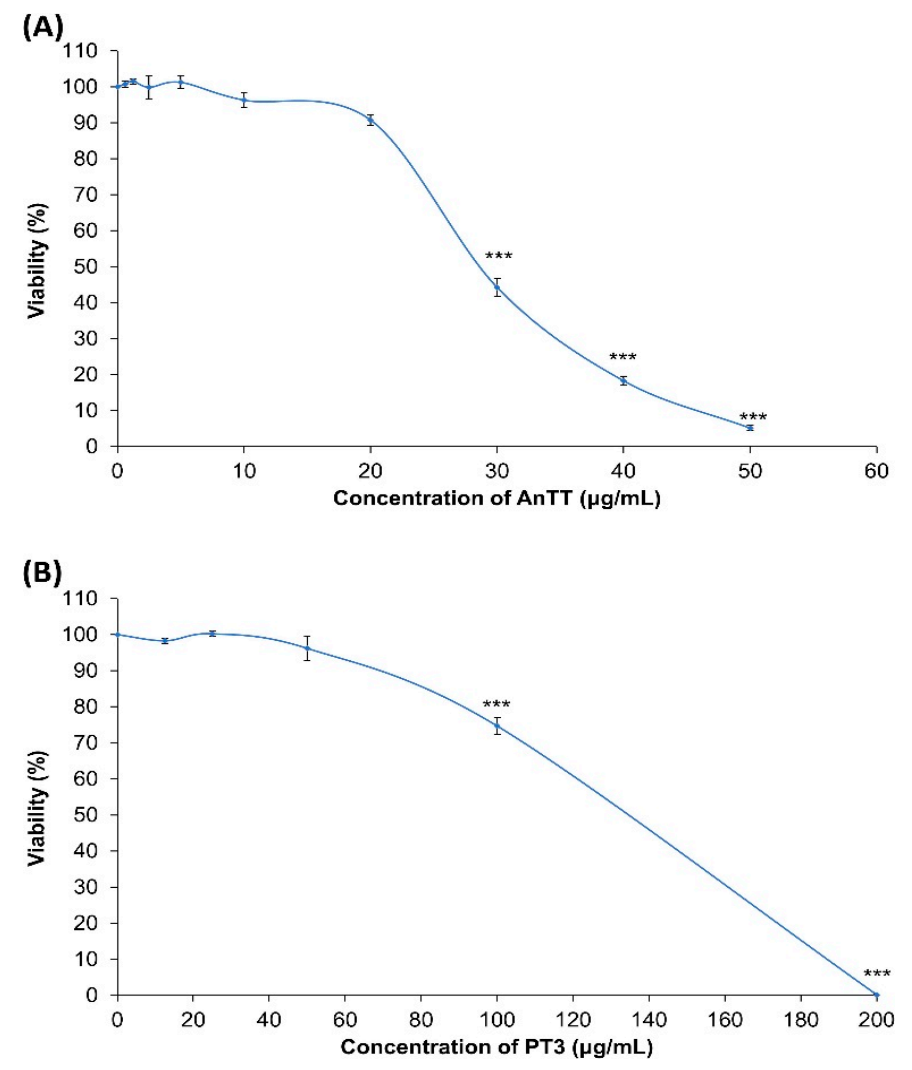

Figure 1. The cytotoxicity of AnTT (A) and PT3 (B) on SW1353 chondrocytes upon $24 \mathrm{~h}$ treatment. The results were obtained from 3 independent experiments with 4 technical replicates during measurement. The data were displayed in mean \pm SEM. ${ }^{* * *}$ indicates a significant difference $(p<0.001)$ compared to the VC $(0 \mu \mathrm{g} / \mathrm{mL})$. 


\subsection{The Effects of AnTT or PT3 Pre-Treatment on MIA-Induced SW1353 Cell Death}

The viability of SW1353 chondrocytes after an initial $24 \mathrm{~h}$ treatment of AnTT or PT3 followed by $24 \mathrm{~h}$ treatment of MIA ( $\mathrm{IC}_{50}: 31.5 \mu \mathrm{M}$ ) was tested (Figure 2). Pre-treatment of AnTT and PT3 did not protect the cells from MIA-induced viability suppression. At higher concentrations, both AnTT ( $\geq 20 \mu \mathrm{g} / \mathrm{mL})$ and PT3 $(\geq 12.5 \mu \mathrm{g} / \mathrm{mL})$ enhanced the toxicity of MIA.

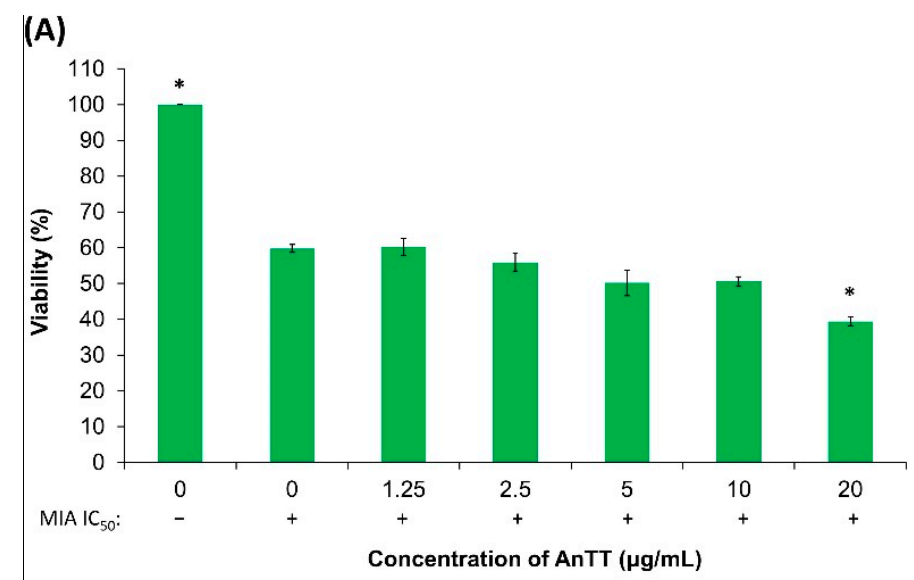

(B)

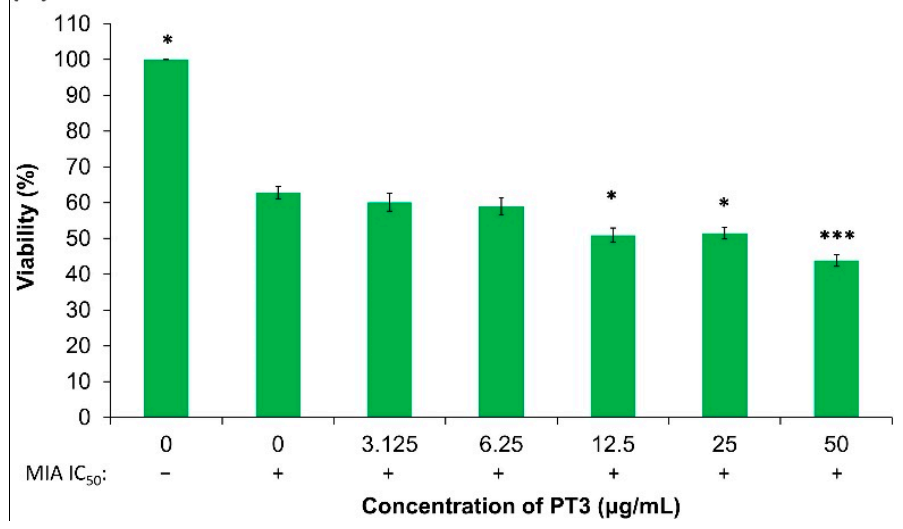

Figure 2. The viability of SW1353 chondrocytes over a $24 \mathrm{~h}$ pre-treatment model with AnTT (A) or PT3 (B), followed by $24 \mathrm{~h}$ treatment of MIA at $\mathrm{IC}_{50}$ of $31.5 \mu \mathrm{M}$. The results were obtained from 3 independent experiments with 4 technical replicates during measurement. The data were displayed in mean \pm SEM. * and ${ }^{* * *}$ indicate a significant difference of $p<0.05$ and $p<0.001$ compared to the MIA control group.

The viability of SW1353 chondrocytes with concurrent treatment of AnTT or PT3 and MIA ( $\left.\mathrm{IC}_{50}: 31.5 \mu \mathrm{M}\right)$ for $24 \mathrm{~h}$ was also tested (Figure 3). In this model, AnTT (10 and $20 \mu \mathrm{g} / \mathrm{mL})$ and PT3 $(3.125,25$ and $50 \mu \mathrm{g} / \mathrm{mL})$ protected the cells from MIA-induced viability suppression by significantly improving the viability of SW1353 chondrocytes (all $p<0.05$ vs. MIA alone). Therefore, these working concentrations of AnTT (10 and $20 \mu \mathrm{g} / \mathrm{mL}$ ) or PT3 (25 and $50 \mu \mathrm{g} / \mathrm{mL}$ ) were used in the subsequent experiments.

\subsection{The Effects of AnTT or PT3 Co-Treatment on 8-Isoprostane F2- $\alpha$ Level}

The 8-isoprostane F2- $\alpha$ level of SW1353 chondrocytes treated for $24 \mathrm{~h}$ with AnTT or PT3 alone, and in combination with MIA (IC50 $31.5 \mu \mathrm{M}$ ) was determined using the ELISA method (Figure 4). The 8 -isoprostane F2- $\alpha$ level increased significantly with MIA treatment on its own $(p<0.05)$. Co-treatment with PT3 $(50 \mu \mathrm{g} / \mathrm{mL})$ or AnTT $(10$ and $20 \mu \mathrm{g} / \mathrm{mL})$ significantly suppressed the increase in 8 -isoprostane F2- $\alpha$ level caused by MIA $(p<0.01)$. 
(A)

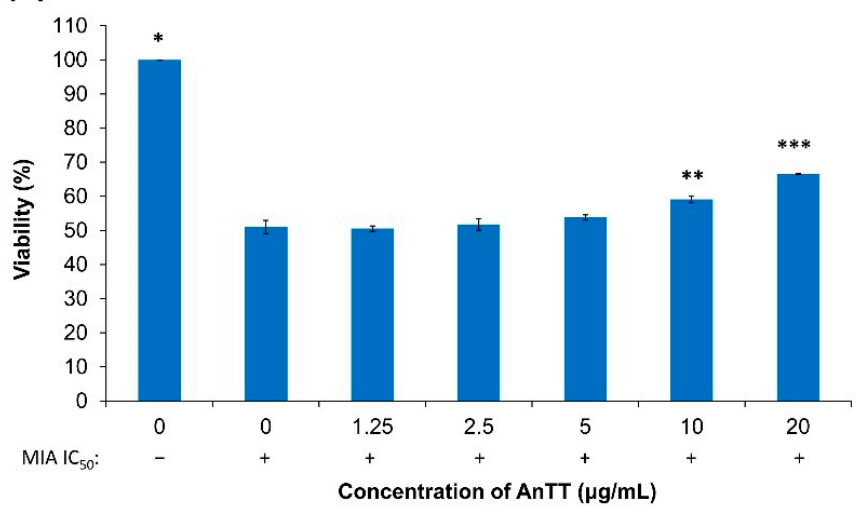

(B)

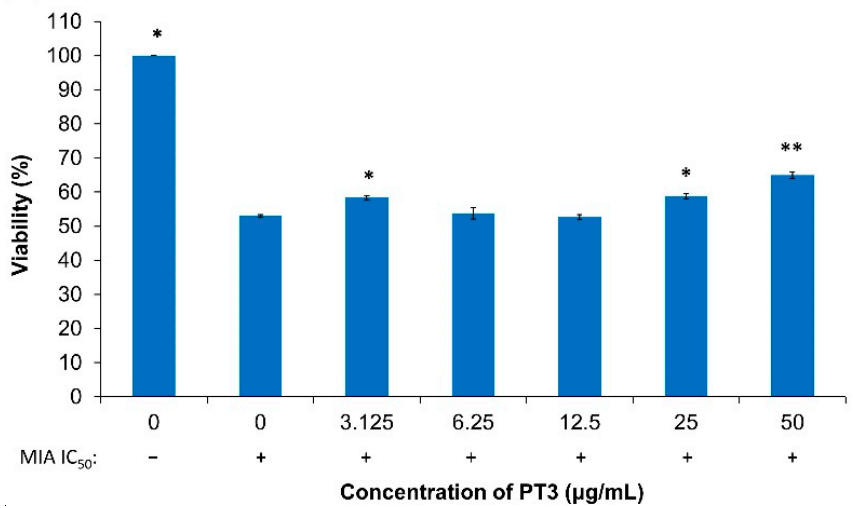

Figure 3. The viability of SW1353 chondrocytes over a $24 \mathrm{~h}$ concurrent treatment of AnTT (A) or PT3 (B) and MIA ( $\mathrm{IC}_{50} 31.5 \mu \mathrm{M}$ ). The results were obtained from 3 independent experiments with 4 technical replicates during measurement. The data were displayed in mean $\pm \mathrm{SEM}$. $^{* * *}$ and ${ }^{* * *}$ indicate a significant difference of $p<0.05, p<0.01$ and $p<0.001$ respectively compared to the MIA control group.

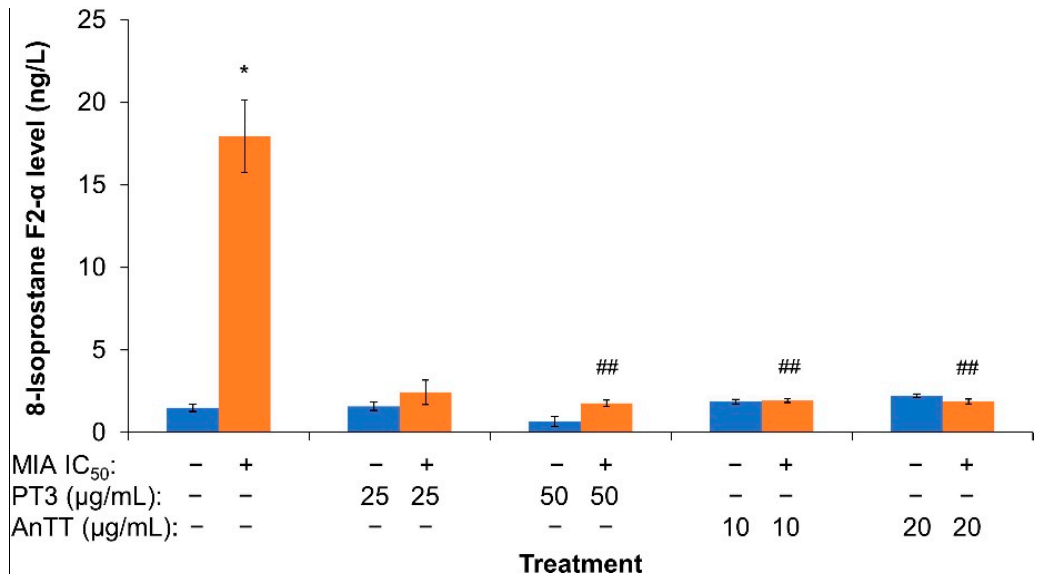

Figure 4. The 8-isoprostane F2- $\alpha$ level of SW1353 chondrocytes treated for $24 \mathrm{~h}$ with AnTT or PT3 alone and in combination with MIA ( $\left.\mathrm{IC}_{50} 31.5 \mu \mathrm{M}\right)$. All results were from 3 independent experiments. Two technical replicates were used during measurement according to manufacturer's instruction. The data were displayed in mean \pm SEM. ${ }^{*}$ indicates a significant difference of $p<0.05$ compared to VC. ${ }^{\#}$ indicates a significant difference of $p<0.01$ compared to the group treated with MIA alone.

The protein expression of COL $1 \alpha 1$, COL2 $\alpha 1$, aggrecan, SOX9 and ADAMTS4 in SW1353 chondrocytes treated for $24 \mathrm{~h}$ with AnTT or PT3 alone, and in combination with 
MIA (IC $5031.5 \mu \mathrm{M})$ were measured using ELISA (Figure 5). MIA $(31.5 \mu \mathrm{M})$ significantly reduced the COL1 $\alpha 1$ and ADAMTS4 levels ( $p<0.05$ vs. VC) without altering the COL2 $\alpha 1$, COL $2 \alpha 1 /$ COL $1 \alpha 1$ index, aggrecan or SOX9 levels ( $p>0.05$ vs. VC). AnTT and PT3 treatment alone did not alter the baseline levels of COL1 $\alpha 1$, COL2 $\alpha 1$, aggrecan and SOX9 ( $p>0.05$ vs. VC or MIA alone) but reduced ADAMTS4 ( $p<0.05$ for AnTT vs. VC) and COL2 $\alpha 1 /$ COL $1 \alpha 1$ indices at higher concentrations ( $p<0.05$ vs. VC). Neither AnTT nor PT3 restored the MIA-induced reduction in COL1 $\alpha 1$ levels ( $p>0.05$ vs. MIA alone) but they did increase the COL2 $\alpha 1 / \operatorname{COL} 1 \alpha 1$ indices for all tested concentrations $(p<0.05 \mathrm{vs}$. MIA alone). Furthermore, PT3 (25 and $50 \mu \mathrm{g} / \mathrm{mL}$ ) also restored the MIA-induced reduction in ADAMTS4 levels ( $p<0.05$ vs. MIA alone). Surprisingly, co-treatment with AnTT and MIA significantly increased SOX9, COL2 $\alpha 1$ and aggrecan levels ( $p<0.05 \mathrm{vs.} \mathrm{MIA} \mathrm{alone).}$
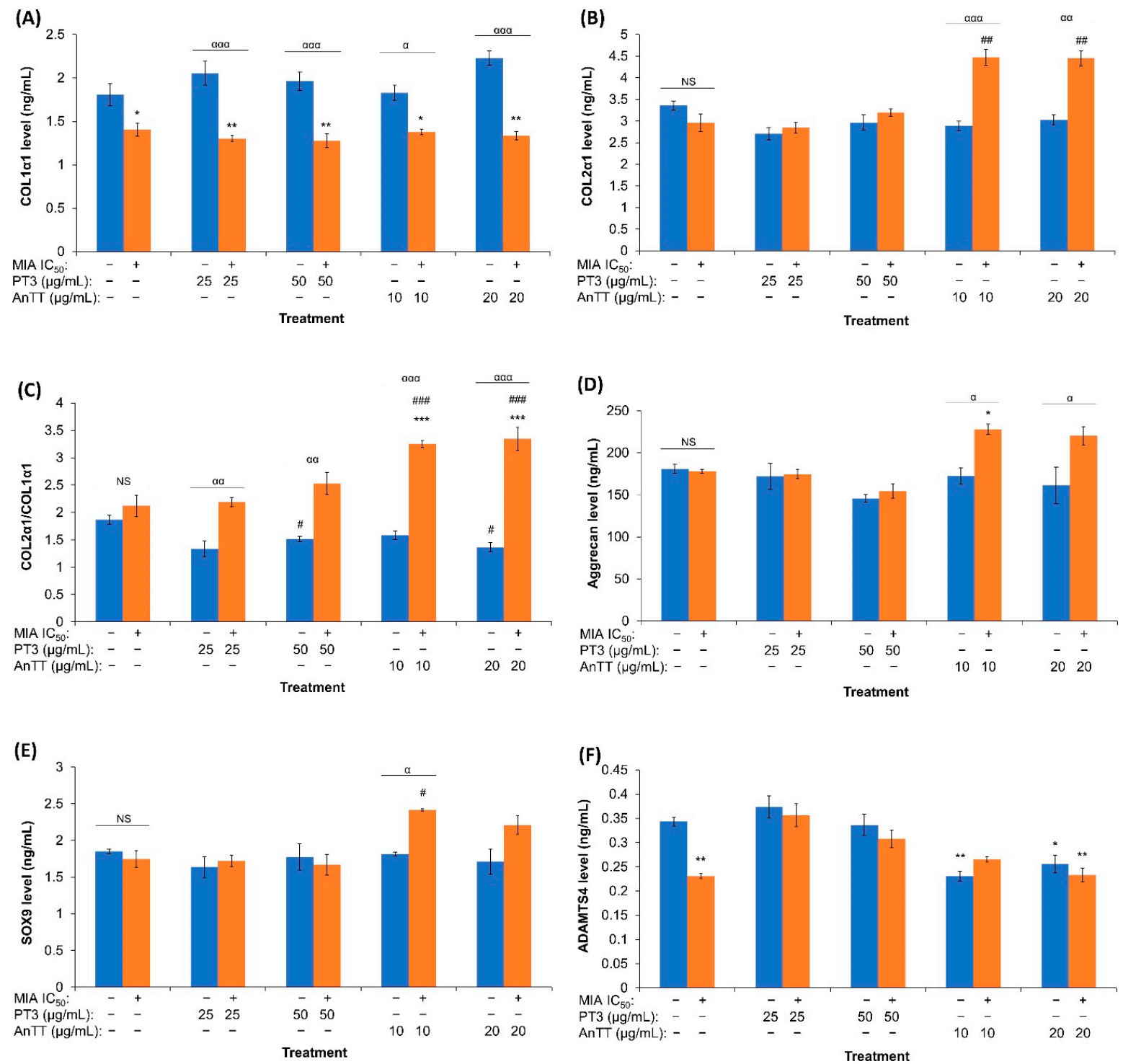

Figure 5. The protein expression of COL1 $\alpha 1$ (A), COL2 $\alpha 1$ (B), COL2 $\alpha 1 /$ COL1 $\alpha 1$ (C), aggrecan (D), SOX9 (E) and ADAMTS4 (F) in SW1353 chondrocytes treated for $24 \mathrm{~h}$ with AnTT or PT3 alone, and in combination with MIA (IC $5031.5 \mu \mathrm{M}$ ). All results were from at least 3 independent experiments. Two technical replicates were used during measurement, according to manufacturer's instruction. The data were displayed in mean \pm SEM. ${ }^{*}, * *$ and ${ }^{* * *}$ indicate a significant difference of $p<0.05, p<0.01$ and $p<0.001$ compared to VC; \# \#\# and \#\#\# indicate a significant difference of $p<0.05, p<0.01$ and $p<0.001$ compared to MIA control; ${ }^{\alpha}, \alpha \alpha$ and ${ }^{\alpha \alpha \alpha}$ indicate a significant difference of $p<0.05, p<0.01$ and $p<0.001$ between group with and without MIA treatment. NS indicates no significant difference between groups. 


\section{Discussion}

The current study showed that MIA decreased the viability of chondrocytes and suppressed COL1 $\alpha 1$ and ADAMST4 levels, but increased the 8-isoprostane F2- $\alpha$ level of chondrocytes. Concurrent incubation with AnTT and PT3 prevented this effect by preventing oxidative damage and improving COL $2 \alpha 1 / \mathrm{COL} 1 \alpha 1$ indices. Prior incubation of chondrocytes with AnTT and PT3 did not achieve the same effects. The concurrent incubation of AnTT and MIA also increased the COL2 $\alpha 1$, aggrecan and SOX9 protein levels in chondrocytes.

The inhibitory effects of MIA on chondrocytes' viability found in this study are consistent with findings in previous literature $[34,35]$. Pang et al. showed that MIA at a similar concentration as the current study $(31.5 \mu \mathrm{M})$ induced a decrease in the viability of SW1353 chondrocytes by proliferation arrest, not cell death [16]. As a glyceraldehyde3-phosphate dehydrogenase inhibitor, MIA reduced the cellular energy production and expression of proteins related to glycolysis in SW1353 chondrocytes [36,37]. It has also been suggested that MIA suppresses the mitophagy process, which clears dysfunctional mitochondria [36]. Furthermore, MIA has been shown to disrupt mitochondria membrane potential and trigger autophagy in chondrocytes in primary rat chondrocytes [35]. These findings might explain how MIA causes the number of viable and functioning chondrocytes to decrease.

The chondroprotective effects of AnTT and PT3 were time-sensitive in this study. Concurrent incubation of AnTT or PT3 and MIA reversed the decrease in the viability of chondrocytes. This observation agrees with a previous animal study by Chin et al. (2019), which reported that treating rats with AnTT immediately after MIA induction protected them from cartilage damage [25]. Another study showed that $\alpha$-tocopherol preserved chondrocytes' morphology in diabetic rats with MIA-induced cartilage damage [38]. It is hypothesised that tocotrienols scavenge free radicals and maintain the intracellular defence against oxidative stress generated by MIA. Co-treatment with zinc, another antioxidant, has also been shown to ameliorate MIA-mediated reduction of chondrocyte viability [28]. However, the present study also showed that pre-treatment of tocotrienol did not offer the same protection. At higher doses, tocotrienol even potentiated the suppressive effects of MIA on cell viability. These findings are in contradiction with previous studies using $\alpha$-tocopherol. Beecher et al. (2007) reported that pre-incubation with $\alpha$-tocopherol for $24 \mathrm{~h}$ preserved the viability of the chondrocytes in human cartilage explants subjected to mechanical stress [39]. Bhatti et al. (2013) treated rat primary chondrocytes with $\alpha$-tocopherol for $24 \mathrm{~h}$ before exposing them to hydrogen peroxide for $3 \mathrm{~h}$ [40]. The intervention preserved viability and the proliferating cell nuclear antigen expression of chondrocytes [40]. It is noteworthy that the MIA-induced chondrocyte damage is mechanistically different from other inducers, such as mechanical stress and hydrogen peroxide, so direct comparison is unattainable. Additionally, since SW1353 is a chondrosarcoma cell line, it is hypothesised that pre-treatment with tocotrienols for $24 \mathrm{~h}$, which are compounds with anticancer properties, could sensitise the cells towards mitochondria dysfunction induced by MIA, independent of their antioxidant properties [41,42]. Thus, the pre-treatment model was not suitable for the objective of this study due to this technical limitation, and the subsequent experiments were conducted using the co-treatment approach.

Oxidative stress contributes to senescence and functional loss of chondrocytes, leading to dysregulation of cartilage haemostasis and subsequent damage $[43,44]$. In this study, MIA induced significant oxidative stress in chondrocytes, as evidenced by an elevated level of 8 -isoprostane F2- $\alpha$, a stable lipid peroxidation marker [45]. The increased oxidative stress was probably a sequela of mitochondrial dysfunction induced by MIA, consistent with previous reports [34,35]. Additionally, MIA also depleted the intracellular glutathione via non-enzymatic binding, which may explain the increase in the endogenous ROS upon induction [37]. Both AnTT and PT3 were shown to suppress MIA-induced lipid peroxidation completely in this study. The function of tocotrienol as a free radical scavenger has been widely reported [46]. The chromanol ring of tocotrienols readily scavenges ROS by 
exchanging electrons with free radicals $[47,48]$, thereby terminating the lipid peroxidation chain reaction. The reduction of oxidative stress by AnTT and PT3 could explain the reversal of MIA-induced viability suppression in chondrocytes.

Collagens and non-collagenous proteins such as aggrecan are the major constituents of the extracellular matrix synthesised by chondrocytes [49]. Type II collagen is a marker of well-differentiated chondrocytes, while type I collagen is a marker of dedifferentiated chondrocytes [50]. Thus, COL2 $\alpha 1 / \operatorname{COL} 1 \alpha 1$ ratio could be used as a marker of chondrocyte differentiation. In this study, MIA caused a significant reduction in COL1 $\alpha 1$ levels but did not alter COL $2 \alpha 1$ and aggrecan levels. In contrast, previous studies have reported that MIA suppressed type II collagen expression [51,52], while increasing type I collagen expression in articular cartilage samples in rats [53]. Other studies have reported a concurrent reduction of type I and type II collagen and aggrecan protein or mRNA expression in articular cartilage samples of rats induced with MIA [54,55]. It is speculated that MIA at the current dose did not overwhelm the repair capacity of chondrocytes, thus the production of type II collagen and aggrecan was preserved at an extent similar to unstimulated chondrocytes.

In this study, AnTT and PT3 alone or PT3 in the presence of MIA did not significantly alter the COL $1 \alpha 1$ and COL $2 \alpha 1$ expressions of the chondrocytes. However, concurrent treatment with AnTT or PT3 with MIA increased the COL2 $\alpha 1 /$ COL $1 \alpha 1$ indices, and it was found that AnTT treatment was more potent despite being at a lower concentration. Unexpectedly, co-treatment of AnTT and MIA stimulated the COL $2 \alpha 1$ and aggrecan expression of the chondrocytes. It is hypothesised that AnTT enhanced the repair response of chondrocytes exposed to MIA. In line with this speculation, it can be suggested that tocotrienols alone did not exert anabolic effects in unstimulated chondrocytes in the current study because the repair response was not activated. By way of comparison, palm vitamin E mixture (Palmvitee) alone was ineffective in preventing the diminished type II collagen expression and the upregulation of type II collagen expression in a monolayer culture of primary chondrocytes from the human nasal septum [56]. However, palm vitamin E mixture promoted type II collagen expression in reconstructed cartilage embedded in vivo [56]. Parallel with our findings, Bhatti et al. demonstrated that pre-treatment of $\alpha$-tocopherol upregulated the expression of gene coding for COL $2 \alpha 1$ and aggrecan, and downregulated gene coding for COL $1 \alpha 1$ in primary chondrocytes exposed to hydrogen peroxide for $3 \mathrm{~h}$. This resulted in an increased COL $2 \alpha 1 / \operatorname{COL} 1 \alpha 1$ ratio in the treated cells [40].

The observations above are supported by the results for SOX9 levels in the chondrocytes treated with both AnTT and MIA. SOX9 is a member of the SRY-related high-mobility group (HMG) box (SOX) family of transcription factors. It plays an important role in chondrogenesis, cell survival and activation of transcription for cartilage components, such as type II collagen and aggrecan [57,58]. MIA administration was reported to suppress SOX9, type II collagen and aggrecan expression in the articular cartilage sample of rats [54,59]. In the current study, MIA exposure alone did not lower the SOX9 level in the chondrocytes, supporting the speculation that chondrocytes might be damaged, but their self-repair mechanism was not overwhelmed. Co-treatment of AnTT and MIA stimulated the expression of SOX9, which coincides with the effects of this treatment on COL $2 \alpha 1$ and aggrecan level. Taken together, these observations suggest that AnTT enhanced chondrocytes' self-repair mechanism when challenged by MIA.

ADAMTS4 is one of the metalloproteinases responsible for the degradation of type II collagen and aggrecan in the cartilage [60]. ADAMTS4 levels in the serum and synovial fluid increases in patients with early-stage OA compared to intermittent and late-stage OA [61,62]. Intra-articular MIA administration has been shown to increase ADAMTS4 expression in rat cartilage samples [63,64]. In this study, MIA exposure led to a significant decrease in ADAMTS4 levels in chondrocytes, probably due to activation of the self-repair mechanism. PT3 $(25 \mu \mathrm{g} / \mathrm{mL})$ restored ADAMTS4 levels in chondrocytes exposed to MIA. It is postulated that PT3 negated the effects of MIA, and the cellular self-repair mechanism 
was not triggered to reduce ADAMTS4 levels. Despite the potential anabolic effects on MIA-induced chondrocytes, as discussed above, AnTT did not normalise ADAMTS4 levels.

Furthermore, we cannot rule out the possibility that the direct chemical interaction between MIA and tocotrienols may partially contribute to the protective effects of tocotrienols during concurrent treatment. Iodoacetate has been demonstrated to bind with nucleophiles such as glutathione or glyceraldehyde-3-phosphate dehydrogenase via electrophilic addition [37]. Furthermore, tocopherol is also reported to bind with mutagenic electrophiles like nitrogen dioxide and peroxynitrite via its electron-rich chromanol ring [65-67]. Tocotrienol, with its similar chromanol ring and a tri-unsaturated aliphatic tail, may serve as a nucleophile in scavenging MIA. Nevertheless, the interaction between tocotrienols and MIA may be minimal, given that concurrent treatment with tocotrienols did not completely abrogate the MIA-mediated cytotoxicity and alteration in metabolism. Therefore, further study is required to confirm the postulated chemical interaction between MIA and tocotrienols.

Comparison between PT3 and AnTT revealed that only AnTT significantly improved the anabolic activities of chondrocytes by increasing the COL $2 \alpha 1 /$ COL $1 \alpha 1$ ratio, SOX9, COL $2 \alpha 1$ and aggrecan levels. AnTT is postulated to enhance the self-repair mechanism of chondrocytes independently of their antioxidant activities. On the other hand, PT3 lowered the MIA-mediated oxidative stress but did not activate the self-repair mechanism, unlike AnTT. Based on the vitamin E isomer constitution, the AnTT-mediated self-repair mechanism may be contributed to by $\delta$-tocotrienol, given that $20 \mu \mathrm{g} / \mathrm{mL}$ AnTT contains a 2.8-fold higher amount of $\delta$-tocotrienol than PT3 $(50 \mu \mathrm{g} / \mathrm{mL})$. The other isomers in PT3, such as $\alpha$-tocopherol and $\alpha$-tocotrienol, may contribute to its antioxidant activities but they did not promote anabolic activities in the chondrocytes. The difference in potency of biological actions for each tocotrienol isomer has been discussed previously [46]. For instance, $\delta$-tocotrienol has been shown to be the most potent isomer in suppressing 3hydroxy-3-methylglutaryl-coenzyme A reductase (HMGCR) [68], activating peroxisome proliferating-activated receptor- $\delta$ or $-\gamma$ [69] and improving insulin synthesis [70].

Additionally, the current study demonstrates the absence of anabolic activities for PT3 at $50 \mu \mathrm{g} / \mathrm{mL}$, despite containing $6 \mu \mathrm{g} / \mathrm{mL} \delta$-tocotrienol, compared to AnTT at $10 \mu \mathrm{g} / \mathrm{mL}$ $(8.4 \mu \mathrm{g} / \mathrm{mL} \delta$-tocotrienol). A potential antagonism interaction is postulated between vitamin E isomers. Tocopherol has been shown to antagonise the action of tocotrienols in lowering lipoprotein and inhibiting HMGCR [71,72]. Interestingly, it has been suggested that HMGCR participates in OA pathogenesis, given that its expression is significantly higher in chondrocytes from OA patients $[73,74]$. Long-term use of statins (HMGCR inhibitors) also significantly reduces the risk of OA among middle-aged adults with cardiovascular diseases [75]. Therefore, the presence of tocopherol in PT3 may hinder the HMGCR-suppressing effects of $\delta$-tocotrienol, which may explain the absence of self-repair and anabolic activities in PT3-MIA co-treated chondrocytes. Further study is required to confirm our speculation and the role of HMGCR in OA initiation, chondrocyte damage and repair mechanisms.

Overall, the current study proposes that AnTT and PT3 prevent the reduction in cell viability of chondrocytes caused by MIA, probably through lowering oxidative stress. AnTT also enhanced the self-repair mechanism of chondrocytes exposed to MIA by activating their anabolic activities, as evidenced by increased COL $2 \alpha 1 /$ COL $1 \alpha 1$ ratios, SOX9, COL $2 \alpha 1$ and aggrecan levels. PT3 does not share the self-repair activation mechanism possessed by AnTT. A summary of the mechanism of actions of AnTT and PT3 on chondrocytes stimulated with MIA is presented in Figure 6.

Several limitations in this study should be addressed. First, the findings of the current study should be validated in more than one chondrocyte cell line and primary mammalian chondrocytes. Second, cartilage explants should be considered, because chondrocytes might behave differently in monolayer and three-dimensional constructs. Third, the enhanced self-repair mechanism of chondrocytes exposed to AnTT and MIA concurrently should be scrutinised, because the current evidence is preliminary. Some studies have reported an adaptive increase in antioxidant response of chondrocytes exposed 
to MIA [34,76]. Forth, silencing of SOX9 could be performed to determine its role in mediating the action of AnTT in promoting chondrocyte repair. Fifth, the ELISA results should be confirmed with a gene expression study or Western blot analysis. Lastly, the chemical interaction between MIA or ROS with AnTT and PT3 should be examined to confirm their upstream protective mechanisms. Nevertheless, the current study suggests the novel action of tocotrienols, especially AnTT, in counteracting chondrocyte damage due to MIA.

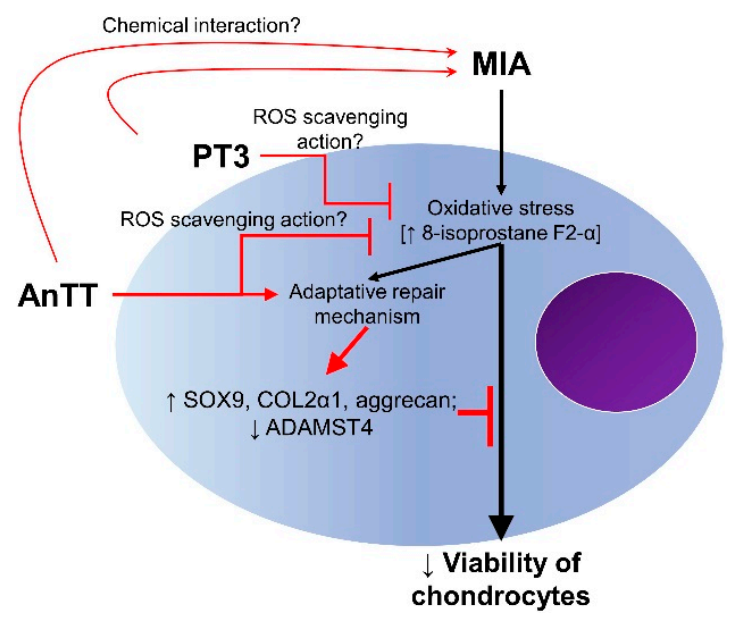

Figure 6. Proposed mechanism of action of tocotrienols on chondrocytes. Both AnTT and PT3 suppress oxidative stress induced by MIA. AnTT also enhances the self-repair mechanism and anabolic activities of chondrocytes exposed to MIA. Abbreviations: $\uparrow$, cause or induce; $\mathrm{T}$, inhibit; AnTT, annatto tocotrienols; COL2 $\alpha 1$, collagen type II $\alpha 1$; PT3, palm tocotrienol-rich fraction; SOX9, sex-determining region $\mathrm{Y}$ box protein 9 .

\section{Conclusions}

Both AnTT and PT3 were found to prevent MIA-induced decreases in the viability of chondrocytes, most likely through their ability to reduce oxidative stress. AnTT possesses additional properties of promoting the self-repair response of chondrocytes exposed to MIA, producing a higher COL $2 \alpha 1 /$ COL $1 \alpha 1$ ratio and higher COL $2 \alpha 1$, SOX 9 and aggrecan levels. AnTT appears to be more effective than PT3 in protecting chondrocytes based on the dose and mechanism of action. Tocotrienol could be developed as a supplement to reduce chondrocyte damage in $\mathrm{OA}$, pending further validation from more comprehensive research.

Author Contributions: Conceptualization, N.A.G., I.N.S. and K.-Y.C.; methodology, K.-L.P.; validation, N.A.G., I.N.S. and K.-Y.C.; formal analysis, K.-L.P. and K.-Y.C.; data curation, K.-L.P.; writing-original draft preparation, K.-L.P.; writing—review and editing, N.A.G., I.N.S. and K.-Y.C.; visualization, K.-L.P. and K.-Y.C.; supervision, K.-Y.C.; funding acquisition, K.-Y.C. All authors have read and agreed to the published version of the manuscript.

Funding: This research was funded by Ministry of Education, Malaysia, grant number FRGS/1/2018/ SKK10/UKM/03/1. Kok-Lun Pang is a postdoctoral researcher funded by Universiti Kebangsaan Malaysia through Postdoctoral Research Scheme (RGA1).

Institutional Review Board Statement: Not applicable.

Informed Consent Statement: Not applicable.

Acknowledgments: The authors acknowledge the Department of Anatomy and the Department of Biochemistry, Faculty of Medicine, Universiti Kebangsaan Malaysia for providing the Multiskan GO microplate reader and flow cytometry facilities.

Conflicts of Interest: The authors declare no conflict of interest. 


\section{References}

1. Ebell, M.H. Osteoarthritis: Rapid Evidence Review. Am. Fam. Physician 2018, 97, 523-526.

2. Cui, A.; Li, H.; Wang, D.; Zhong, J.; Chen, Y.; Lu, H. Global, regional prevalence, incidence and risk factors of knee osteoarthritis in population-based studies. EClinicalMedicine 2020, 29-30, 100587. [CrossRef]

3. Global Burden of Disease Collaborative Network. Global Burden of Disease Study 2019 (GBD 2019) Results. Osteoarthritis —Level 3 Cause. Available online: http://www.healthdata.org/results/gbd_summaries/2019/osteoarthritis-level-3-cause (accessed on 15 June 2021).

4. Wang, H.; Bai, J.; He, B.; Hu, X.; Liu, D. Osteoarthritis and the risk of cardiovascular disease: A meta-analysis of observational studies. Sci. Rep. 2016, 6, 39672. [CrossRef]

5. Veronese, N.; Cereda, E.; Maggi, S.; Luchini, C.; Solmi, M.; Smith, T.; Denkinger, M.; Hurley, M.; Thompson, T.; Manzato, E.; et al. Osteoarthritis and mortality: A prospective cohort study and systematic review with meta-analysis. Semin. Arthritis Rheum. 2016, 46, 160-167. [CrossRef]

6. Hwang, H.S.; Kim, H.A. Chondrocyte Apoptosis in the Pathogenesis of Osteoarthritis. Int. J. Mol. Sci. 2015, 16, 26035-26054. [CrossRef]

7. Zamli, Z.; Sharif, M. Chondrocyte apoptosis: A cause or consequence of osteoarthritis? Int. J. Rheum. Dis. 2011, 14, 159-166. [CrossRef]

8. Mobasheri, A. Role of chondrocyte death and hypocellularity in ageing human articular cartilage and the pathogenesis of osteoarthritis. Med. Hypotheses 2002, 58, 193-197. [CrossRef] [PubMed]

9. Fernandes, T.L.; Gomoll, A.H.; Lattermann, C.; Hernandez, A.J.; Bueno, D.F.; Amano, M.T. Macrophage: A Potential Target on Cartilage Regeneration. Front. Immunol. 2020, 11, 111. [CrossRef] [PubMed]

10. Chin, K.Y.; Pang, K.L. Therapeutic Effects of Olive and Its Derivatives on Osteoarthritis: From Bench to Bedside. Nutrients 2017, 9 , 1060. [CrossRef] [PubMed]

11. Van der Kraan, P.M.; van den Berg, W.B. Chondrocyte hypertrophy and osteoarthritis: Role in initiation and progression of cartilage degeneration? Osteoarthr. Cartil. 2012, 20, 223-232. [CrossRef]

12. Charlier, E.; Relic, B.; Deroyer, C.; Malaise, O.; Neuville, S.; Collée, J.; Malaise, M.G.; De Seny, D. Insights on Molecular Mechanisms of Chondrocytes Death in Osteoarthritis. Int. J. Mol. Sci. 2016, 17, 2146. [CrossRef]

13. Robinson, W.H.; Lepus, C.M.; Wang, Q.; Raghu, H.; Mao, R.; Lindstrom, T.M.; Sokolove, J. Low-grade inflammation as a key mediator of the pathogenesis of osteoarthritis. Nat. Rev. Rheumatol 2016, 12, 580-592. [CrossRef]

14. Lambert, C.; Zappia, J.; Sanchez, C.; Florin, A.; Dubuc, J.-E.; Henrotin, Y. The Damage-Associated Molecular Patterns (DAMPs) as Potential Targets to Treat Osteoarthritis: Perspectives From a Review of the Literature. Front. Med. 2021, 7, 607186. [CrossRef] [PubMed]

15. Kim, J.; Xu, M.; Xo, R.; Mates, A.; Wilson, G.L.; Pearsall, A.W.; Grishko, V. Mitochondrial DNA damage is involved in apoptosis caused by pro-inflammatory cytokines in human OA chondrocytes. Osteoarthr. Cartil. 2010, 18, 424-432. [CrossRef] [PubMed]

16. Pang, K.L.; Chow, Y.Y.; Leong, L.M.; Law, J.X.; Ghafar, N.A.; Soelaiman, I.N.; Chin, K.Y. Establishing SW1353 Chondrocytes as a Cellular Model of Chondrolysis. Life 2021, 11, 272. [CrossRef] [PubMed]

17. Kolasinski, S.L.; Neogi, T.; Hochberg, M.C.; Oatis, C.; Guyatt, G.; Block, J.; Callahan, L.; Copenhaver, C.; Dodge, C.; Felson, D.; et al. 2019 American College of Rheumatology/Arthritis Foundation Guideline for the Management of Osteoarthritis of the Hand, Hip, and Knee. Arthritis Care Res. 2020, 72, 149-162. [CrossRef]

18. Richards, M.M.; Maxwell, J.S.; Weng, L.; Angelos, M.G.; Golzarian, J. Intra-articular treatment of knee osteoarthritis: From anti-inflammatories to products of regenerative medicine. Phys. Sportsmed. 2016, 44, 101-108. [CrossRef]

19. Liu, X.; Machado, G.C.; Eyles, J.P.; Ravi, V.; Hunter, D.J. Dietary supplements for treating osteoarthritis: A systematic review and meta-analysis. Br. J. Sports Med. 2018, 52, 167-175. [CrossRef] [PubMed]

20. Tyagi, V.; Farooq, M. Unicompartmental Knee Arthroplasty: Indications, Outcomes, and Complications. Conn. Med. 2017, 81, 87-90.

21. Gui, Q.; Zhang, X.; Liu, L.; Zhao, F.; Cheng, W.; Zhang, Y. Cost-utility analysis of total knee arthroplasty for osteoarthritis in a regional medical center in China. Health Econ. Rev. 2019, 9, 15. [CrossRef]

22. Haleagrahara, N.; Swaminathan, M.; Chakravarthi, S.; Radhakrishnan, A. Therapeutic efficacy of vitamin E $\delta$-tocotrienol in collagen-induced rat model of arthritis. Biomed Res. Int. 2014, 2014, 539540. [CrossRef]

23. Radhakrishnan, A.; Tudawe, D.; Chakravarthi, S.; Chiew, G.S.; Haleagrahara, N. Effect of $\gamma$-tocotrienol in counteracting oxidative stress and joint damage in collagen-induced arthritis in rats. Exp. Ther. Med. 2014, 7, 1408-1414. [CrossRef] [PubMed]

24. Zainal, Z.; Rahim, A.A.; Radhakrishnan, A.K.; Chang, S.K.; Khaza'ai, H. Investigation of the curative effects of palm vitamin E tocotrienols on autoimmune arthritis disease in vivo. Sci. Rep. 2019, 9, 16793. [CrossRef] [PubMed]

25. Chin, K.Y.; Wong, S.K.; Japar Sidik, F.Z.; Abdul Hamid, J.; Abas, N.H.; Mohd Ramli, E.S.; Afian Mokhtar, S.; Rajalingham, S.; Ima Nirwana, S. The Effects of Annatto Tocotrienol Supplementation on Cartilage and Subchondral Bone in an Animal Model of Osteoarthritis Induced by Monosodium Iodoacetate. Int. J. Environ. Res. Public Health 2019, 16, 2897. [CrossRef] [PubMed]

26. Al-Saadi, H.M.; Chin, K.-Y.; Ahmad, F.; Mohd Ramli, E.S.; Arlamsyah, A.M.; Japar Sidik, F.Z.; Abdul Hamid, J.; Soelaiman, I.N. Effects of Palm Tocotrienol-Rich Fraction Alone or in Combination with Glucosamine Sulphate on Grip Strength, Cartilage Structure and Joint Remodelling Markers in a Rat Model of Osteoarthritis. Appl. Sci. 2021, 11, 8577. [CrossRef] 
27. Chin, K.Y.; Ima-Nirwana, S. The Role of Vitamin E in Preventing and Treating Osteoarthritis-A Review of the Current Evidence. Front. Pharm. 2018, 9, 946. [CrossRef]

28. Frega, N.; Mozzon, M.; Bocci, F. Identification and estimation of tocotrienols in the annatto lipid fraction by gas chromatographymass spectrometry. J. Am. Oil Chem. Soc. 1998, 75, 1723-1727. [CrossRef]

29. Sundram, K.; Sambanthamurthi, R.; Tan, Y.A. Palm fruit chemistry and nutrition. Asia Pac. J. Clin. Nutr 2003, 12, 355-362. [PubMed]

30. Wan Hasan, W.N.; Abd Ghafar, N.; Chin, K.-Y.; Ima-Nirwana, S. Annatto-derived tocotrienol stimulates osteogenic activity in preosteoblastic MC3T3-E1 cells: A temporal sequential study. Drug Des. Dev. Ther. 2018, 12, 1715-1726. [CrossRef]

31. Wan Hasan, W.N.; Chin, K.Y.; Abd Ghafar, N.; Soelaiman, I.N. Annatto-Derived Tocotrienol Promotes Mineralization of MC3T3-E1 Cells by Enhancing BMP-2 Protein Expression via Inhibiting RhoA Activation and HMG-CoA Reductase Gene Expression. Drug Des. Dev. Ther. 2020, 14, 969-976. [CrossRef]

32. Fauzi, S.; Rajab, N.; Leong, L.; Pang, K.; Nawi, N.; Nasir, N.; Lorin, F.; Yusof, F. Apoptosis and cell cycle effect of Lignosus rhinocerus extract on HCT 116 human colorectal cancer cells. Int. J. Pharm. Sci. Rev. Res. 2015, 33, $13-17$.

33. Osborne, J. Improving your data transformations: Applying the Box-Cox transformation. Pract. Assess. Res. Eval. 2010, 15, 12. [CrossRef]

34. Huang, T.C.; Chang, W.T.; Hu, Y.C.; Hsieh, B.S.; Cheng, H.L.; Yen, J.H.; Chiu, P.R.; Chang, K.L. Zinc Protects Articular Chondrocytes through Changes in Nrf2-Mediated Antioxidants, Cytokines and Matrix Metalloproteinases. Nutrients 2018, 10, 471. [CrossRef] [PubMed]

35. Jiang, L.; Li, L.; Geng, C.; Gong, D.; Jiang, L.; Ishikawa, N.; Kajima, K.; Zhong, L. Monosodium iodoacetate induces apoptosis via the mitochondrial pathway involving ROS production and caspase activation in rat chondrocytes in vitro. J. Orthop. Res. 2013, 31, 364-369. [CrossRef] [PubMed]

36. Huang, L.-W.; Huang, T.-C.; Hu, Y.-C.; Hsieh, B.-S.; Chiu, P.-R.; Cheng, H.-L.; Chang, K.-L. Zinc protects chondrocytes from monosodium iodoacetate-induced damage by enhancing ATP and mitophagy. Biochem. Biophys. Res. Commun. 2020, 521, 50-56. [CrossRef] [PubMed]

37. Schmidt, M.; Dringen, R. Differential Effects of Iodoacetamide and Iodoacetate on Glycolysis and Glutathione Metabolism of Cultured Astrocytes. Front. Neuroenergetics 2009, 1, 1. [CrossRef] [PubMed]

38. Hassan, W.N.; Bin-Jaliah, I.; Haidara, M.A.; Eid, R.A.; Heidar, E.H.A.; Dallak, M.; Al-Ani, B. Vitamin E ameliorates alterations to the articular cartilage of knee joints induced by monoiodoacetate and diabetes mellitus in rats. Ultrastruct Pathol. 2019, 43, 126-134. [CrossRef]

39. Beecher, B.R.; Martin, J.A.; Pedersen, D.R.; Heiner, A.D.; Buckwalter, J.A. Antioxidants block cyclic loading induced chondrocyte death. Iowa Orthop. J. 2007, 27, 1-8.

40. Bhatti, F.U.R.; Mehmood, A.; Wajid, N.; Rauf, M.; Khan, S.N.; Riazuddin, S. Vitamin e protects chondrocytes against hydrogen peroxide-induced oxidative stress in vitro. Inflamm. Res. 2013, 62, 781-789. [CrossRef]

41. Xu, W.; Mi, Y.; He, P.; He, S.; Niu, L. $\gamma$-Tocotrienol Inhibits Proliferation and Induces Apoptosis Via the Mitochondrial Pathway in Human Cervical Cancer HeLa Cells. Molecules 2017, 22, 1299. [CrossRef]

42. Fontana, F.; Raimondi, M.; Marzagalli, M.; Audano, M.; Beretta, G.; Procacci, P.; Sartori, P.; Mitro, N.; Limonta, P. Mitochondrial functional and structural impairment is involved in the antitumor activity of $\delta$-tocotrienol in prostate cancer cells. Free Radic. Biol. Med. 2020, 160, 376-390. [CrossRef] [PubMed]

43. Zahan, O.-M.; Serban, O.; Gherman, C.; Fodor, D. The evaluation of oxidative stress in osteoarthritis. Med. Pharm. Rep. 2020, 93, 12-22. [CrossRef] [PubMed]

44. Lepetsos, P.; Papavassiliou, K.A.; Papavassiliou, A.G. Redox and NF-кB signaling in osteoarthritis. Free Radic. Biol. Med. 2019, 132, 90-100. [CrossRef] [PubMed]

45. Roberts, L.J.; Morrow, J.D. Measurement of F(2)-isoprostanes as an index of oxidative stress in vivo. Free Radic. Biol. Med. 2000, 28, 505-513. [CrossRef]

46. Wong, S.K.; Kamisah, Y.; Mohamed, N.; Muhammad, N.; Masbah, N.; Fahami, N.A.M.; Mohamed, I.N.; Shuid, A.N.; Saad, Q.M.; Abdullah, A.; et al. Potential Role of Tocotrienols on Non-Communicable Diseases: A Review of Current Evidence. Nutrients 2020, 12, 259. [CrossRef]

47. Gruszka, J.; Pawlak, A.; Kruk, J. Tocochromanols, plastoquinol, and other biological prenyllipids as singlet oxygen quenchersdetermination of singlet oxygen quenching rate constants and oxidation products. Free Radic. Biol. Med. 2008, 45, 920-928. [CrossRef]

48. Housam, H.; Warid, K.; Zaid, A. Estimating the antioxidant activity for natural antioxidants (tocochromanol) and synthetic one by DPPH. Int. J. Pharm. Pharm. Sci. 2014, 5, 441-444.

49. Carballo, C.B.; Nakagawa, Y.; Sekiya, I.; Rodeo, S.A. Basic science of articular cartilage. Clin. Sports Med. 2017, 36, 413-425. [CrossRef]

50. Marlovits, S.; Hombauer, M.; Truppe, M.; Vecsei, V.; Schlegel, W. Changes in the ratio of type-I and type-II collagen expression during monolayer culture of human chondrocytes. J. Bone Jt. Surg Br. 2004, 86, 286-295. [CrossRef] 
51. Lu, J.; Zhang, T.; Sun, H.; Wang, S.; Liu, M. Protective effects of dioscin against cartilage destruction in a monosodium iodoacetate (MIA)-indcued osteoarthritis rat model. Biomed. Pharm. 2018, 108, 1029-1038. [CrossRef]

52. Lee, H.; Choi, H.-S.; Park, Y.; Ahn, C.W.; Jung, S.U.; Park, S.H.; Suh, H.J. Effects of deer bone extract on the expression of pro-inflammatory cytokine and cartilage-related genes in monosodium iodoacetate-induced osteoarthritic rats. Biosci. Biotechnol. Biochem. 2014, 78, 1703-1709. [CrossRef] [PubMed]

53. Chun, J.M.; Lee, A.Y.; Nam, J.Y.; Lim, K.S.; Choe, M.S.; Lee, M.Y.; Kim, C.; Kim, J.-S. Effects of Dipsacus asperoides Extract on Monosodium Iodoacetate-Induced Osteoarthritis in Rats Based on Gene Expression Profiling. Front. Pharm. 2021, $12,615157$. [CrossRef] [PubMed]

54. Kim, H.L.; Lee, H.J.; Lee, D.-R.; Choi, B.-K.; Yang, S.H. Anti-Osteoarthritic Effects of Terminalia Chebula Fruit Extract (AyuFlex ${ }^{\circledR}$ ) in Interleukin-1 $\beta$-Induced Human Chondrocytes and in Rat Models of Monosodium Iodoacetate (MIA)-Induced Osteoarthritis. Appl. Sci. 2020, 10, 8698. [CrossRef]

55. Lee, M.; Kim, D.; Park, S.-J.; Yun, J.m.; Oh, D.H.; Lee, J. Antarctic Krill Oil Ameliorates Monosodium Iodoacetate-Induced Irregularities in Articular Cartilage and Inflammatory Response in the Rat Models of Osteoarthritis. Nutrients 2020, $12,3550$. [CrossRef]

56. Ruszymah, B.; Aminuddin, B.; Gapor, A.; Fuzina, H. The Effects of Palmvitee on Human Nasal Septal Chondrocytes Culture Expansion and Cartilage Reconstruction. ASEAN J. Sci. Technol. Dev. 2005, 22, 211-222. [CrossRef]

57. Lefebvre, V.; Dvir-Ginzberg, M. SOX9 and the many facets of its regulation in the chondrocyte lineage. Connect. Tissue Res. 2017, 58, 2-14. [CrossRef]

58. Song, H.; Park, K.-H. Regulation and function of SOX9 during cartilage development and regeneration. Semin. Cancer Biol. 2020, 67, 12-23. [CrossRef] [PubMed]

59. Choudhary, D.; Kothari, P.; Tripathi, A.K.; Singh, S.; Adhikary, S.; Ahmad, N.; Kumar, S.; Dev, K.; Mishra, V.K.; Shukla, S.; et al Spinacia oleracea extract attenuates disease progression and sub-chondral bone changes in monosodium iodoacetate-induced osteoarthritis in rats. BMC Complement. Altern. Med. 2018, 18, 69. [CrossRef]

60. Yang, C.Y.; Chanalaris, A.; Troeberg, L. ADAMTS and ADAM metalloproteinases in osteoarthritis-Looking beyond the 'usual suspects'. Osteoarthr. Cartil. 2017, 25, 1000-1009. [CrossRef]

61. Li, W.; Du, C.; Wang, H.; Zhang, C. Increased serum ADAMTS-4 in knee osteoarthritis: A potential indicator for the diagnosis of osteoarthritis in early stages. Genet. Mol. Res. 2014, 13, 9642-9649. [CrossRef]

62. Zhang, E.; Yan, X.; Zhang, M.; Chang, X.; Bai, Z.; He, Y.; Yuan, Z. Aggrecanases in the human synovial fluid at different stages of osteoarthritis. Clin. Rheumatol. 2013, 32, 797-803. [CrossRef]

63. Chun, J.M.; Lee, A.Y.; Nam, J.Y.; Lee, M.Y.; Choe, M.S.; Lim, K.S.; Kim, C.; Kim, J.-S. Protective effects of Phlomis umbrosa extract on a monosodium iodoacetate-induced osteoarthritis model and prediction of molecular mechanisms using transcriptomics. Phytomedicine 2021, 81, 153429. [CrossRef]

64. Li, H.; Xie, S.; Qi, Y.; Li, H.; Zhang, R.; Lian, Y. TNF- $\alpha$ increases the expression of inflammatory factors in synovial fibroblasts by inhibiting the PI3K/AKT pathway in a rat model of monosodium iodoacetate-induced osteoarthritis. Exp. Ther. Med. 2018, 16, 4737-4744. [CrossRef]

65. Christen, S.; Woodall, A.A.; Shigenaga, M.K.; Southwell-Keely, P.T.; Duncan, M.W.; Ames, B.N. Gamma-tocopherol traps mutagenic electrophiles such as $\mathrm{NO}(\mathrm{X})$ and complements alpha-tocopherol: Physiological implications. Proc. Natl. Acad. Sci. USA 1997, 94, 3217-3222. [CrossRef] [PubMed]

66. Cooney, R.V.; Harwood, P.J.; Franke, A.A.; Narala, K.; Sundström, A.-K.; Berggren, P.-O.; Mordan, L.J. Products of $\gamma$-tocopherol reaction with NO2 and their formation in rat insulinoma (RINm5F) cells. Free Radic. Biol. Med. 1995, 19, 259-269. [CrossRef]

67. Cooney, R.V.; Franke, A.A.; Harwood, P.J.; Hatch-Pigott, V.; Custer, L.J.; Mordan, L.J. Gamma-tocopherol detoxification of nitrogen dioxide: Superiority to alpha-tocopherol. Proc. Natl. Acad. Sci. USA 1993, 90, 1771-1775. [CrossRef]

68. Salman Khan, M.; Akhtar, S.; Al-Sagair, O.A.; Arif, J.M. Protective effect of dietary tocotrienols against infection and inflammationinduced hyperlipidemia: An in vivo and in silico study. Phytother. Res. 2011, 25, 1586-1595. [CrossRef]

69. Fang, F.; Kang, Z.; Wong, C. Vitamin E tocotrienols improve insulin sensitivity through activating peroxisome proliferatoractivated receptors. Mol. Nutr. Food Res. 2010, 54, 345-352. [CrossRef]

70. Chia, L.L.; Jantan, I.; Chua, K.H.; Lam, K.W.; Rullah, K.; Aluwi, M.F. Effects of tocotrienols on insulin secretion-associated genes expression of rat pancreatic islets in a dynamic culture. Front. Pharmacol. 2016, 7, 291. [CrossRef] [PubMed]

71. Qureshi, A.A.; Bradlow, B.A.; Brace, L.; Manganello, J.; Peterson, D.M.; Pearce, B.C.; Wright, J.J.; Gapor, A.; Elson, C.E. Response of hypercholesterolemic subjects to administration of tocotrienols. Lipids 1995, 30, 1171-1177. [CrossRef] [PubMed]

72. Qureshi, A.A.; Pearce, B.C.; Nor, R.M.; Gapor, A.; Peterson, D.M.; Elson, C.E. Dietary alpha-tocopherol attenuates the impact of gamma-tocotrienol on hepatic 3-hydroxy-3-methylglutaryl coenzyme A reductase activity in chickens. J. Nutr. 1996, 126, 389-394. [CrossRef] [PubMed]

73. Kostopoulou, F.; Gkretsi, V.; Malizos, K.; Iliopoulos, D.; Oikonomou, P.; Poultsides, L.; Tsezou, A. Central Role of SREBP-2 in the Pathogenesis of Osteoarthritis. PLoS ONE 2012, 7, e35753. [CrossRef] [PubMed]

74. Tao, K., Sr.; Tang, X.; Wang, B.; Li, J.R.; Jiang, L.; Lin, H.J. Distinct expression of SREBP-2 in normal and osteoarthritic chondrocytes. Osteoarthr. Cartil. 2015, 23, A162. [CrossRef] 
75. Kadam, U.T.; Blagojevic, M.; Belcher, J. Statin use and clinical osteoarthritis in the general population: A longitudinal study. J. Gen. Intern. Med. 2013, 28, 943-949. [CrossRef] [PubMed]

76. Cifuentes, D.J.; Rocha, L.G.; Silva, L.A.; Brito, A.C.; Rueff-Barroso, C.R.; Porto, L.C.; Pinho, R.A. Decrease in oxidative stress and histological changes induced by physical exercise calibrated in rats with osteoarthritis induced by monosodium iodoacetate. Osteoarthr. Cartil. 2010, 18, 1088-1095. [CrossRef] 